\title{
Organic cotton finding a niche in northern San Joaquin
}

laude Sheppard decided to try out Inte-

grated Pest Management (IPM) on his

Chowchilla cotton farm over a decade ago at the urging of his pregnant wife.

"The crop did so well that we didn't have to apply any insecticides," Sheppard says. A few years after that he quit using synthetic pesticides altogether. "We decided to try an organic crop, and it worked too," the grower explains.

Then in 1993, Sean Swezey, UC Santa Cruz extension specialist and recently appointed director of the UC Sustainable Agriculture Research and Education Program (SAREP), began monitoring Sheppard's organic cotton crops.

In a 3-year, field-level comparison, Swezey and colleagues found no significant differences in lint yields between the organic and conventional cotton production systems in a small study area in the northern San Joaquin Valley. They also found significantly higher counts of beneficial insects in the organic fields. In the one year in which researchers compared color grades (1994), they were more variable in the organic fields. The results are published in this issue of California Agriculture (see p. 9).

Organic cotton makes up a fraction of a percent of cotton acreage in the United States, but it is increasing. Nationally, 16,400 acres of transitional and organic cotton were planted in seven states in 1999, up from 900 acres in 1990, according to the Organic Trade Association's Organic Fiber Council (OFC). (About 14 million acres of cotton were planted nationwide.) In California this year, about 1,083 transitional (farmed organically, but not certified) and certified organic acres were planted by five growers, out of 885,000 total acres in the state.

Certified organic Upland cotton consistently garners double the price of conventional cotton, about $\$ 1.10$ to $\$ 1.25$ per pound versus 50 cents to 60 cents per pound. But organic production costs are higher, the markets have been unstable, and in subsequent studies in the same region (not yet published), Swezey is finding that organic yields run about a quarter to a half bale lower than conventional crops.

\section{First peer-reviewed study}

Swezey's work is perhaps the first peerreviewed, published study to directly compare organic and conventional cotton production in California at the field level. The current study

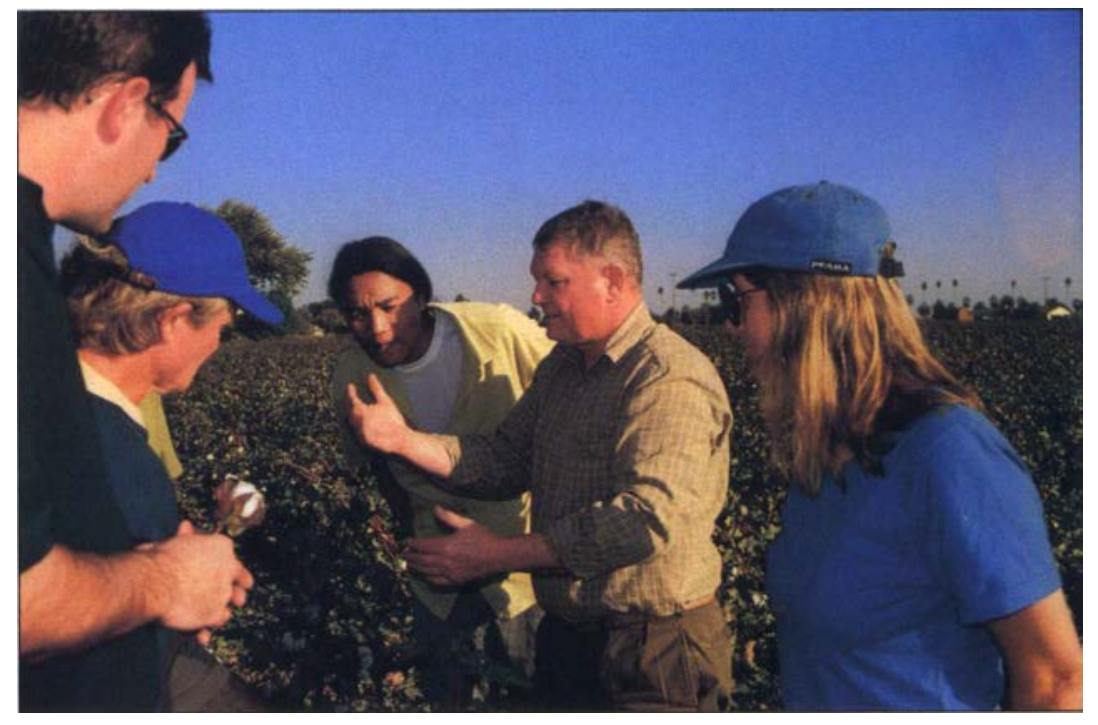

analyzes samples from four organic and four conventional fields for pest and beneficial arthropod populations, growth and development parameters, nutrient status, plant density, yields and lint quality.

The insect monitoring results from Sheppard's fields were unexpected, Swezey says. "I was surprised that it was feasible to produce cotton without insecticides at all."

In the northern San Joaquin Valley, Swezey believes the presence of alfalfa crops "insulate organic growers from the absolute requirement" to use synthetic pesticides by acting as a "sink" for lygus bugs, a serious cotton pest.

"We need to look at the ecology of the entire region," Swezey says.

Peter Goodell of the UC Statewide IPM Project agrees that managing lygus bugs in regional ecosystems is key in cotton production, because there are no environmentally friendly, selective insecticides available for the destructive pest. "As lygus management goes, so goes all cotton insect management," Goodell says.

\section{Lower yields in follow-up}

Swezey's group is in the middle of a 5-year follow-up study (1996 to 2001), with a larger sample of organic and IPM cotton growers. These growers are participants in the Biological Agricultural Systems in Cotton (BASIC) program, sponsored by the private group, Sustainable Cotton Project (SCP). UC researchers, including UC Santa Cruz postgraduate Polly
Sustainable Cotton Project tour of Claude Sheppard's 600-acre organic cotton farm in Chowchilla. Left to right are Quintin Shuler, Parkdale Mills; Will Allen, executive director, Sustainable Cotton Project; Lhakpa Sherpa, Patagonia's San Francisco store; Sheppard; and agricultural consultant Jo Ann Baumgartner. 


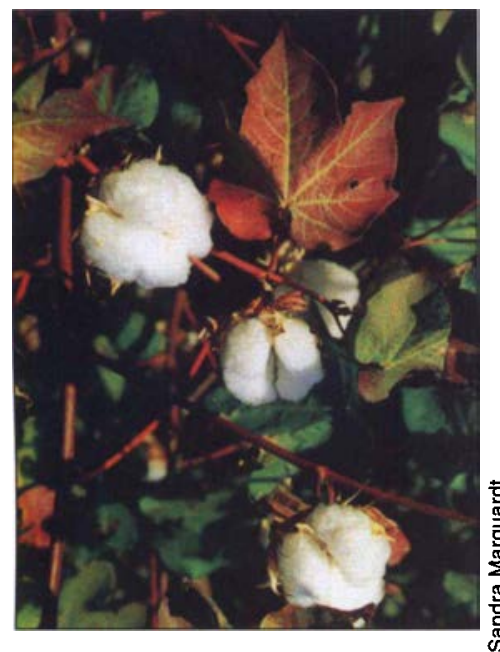

Organic cotton bolls.
Goldman, have also been surveying farmers to evaluate the economics of organic cotton production and assess energy use levels.

Swezey noted that of the 3 years $(1993$ to 1995) in the earlier study, planting weather was irregular in 1994 and 1995 and there were low yields ( 2 bales per acre) for all Madera County cotton in 1995. In the follow-up study, he is finding that organic production yields a quarter to half bale less (about 2.2 bales per acre) than the of countywide averages for conventionally produced cotton in a normal weather year.

"I feel confident that yield gap can be closed, by a research effort dedicated to the problems of efficacious weed control and crop preparation for organic cotton," Swezey says.

Five BASIC growers utilizing IPM on 1,200 acres in the northern San Joaquin Valley were able to reduce their total annual insecticide/ miticide usage from 17,628 pounds to 1,244 pounds during the 1996 to 1997 growing season, according to SCP. Their yields were about 2.5 bales per acre, compared with 2.1 bales for organic production and 2.85 for conventional.

\section{Markets an obstacle}

It takes 3 years for a conventional farm to transition to certified organic production and receive a premium price. The main reason farmers are reluctant to invest in the transition is because the market for organic fiber has been unstable in the 1990s, SCP executive director Will Allen says. "A lot of our IPM growers would like to go organic, but there's no market."

Sheppard, who farms organic cotton on 600 acres, says the market for his product is "there some years and some years it's not." Organic cotton can be sold on the conventional market, but at a loss; it can also be held in storage until buyers become available, Sheppard says.

U.S. organic cotton acreage grew steadily in the early 1990 s to nearly 25,000 transitional and organic acres in 1995, when two major buyers (Esprit and Vanity Fair) discontinued their purchasing of organic cotton. About 11,000 acres were planted in the United States in 1996, and the number has again been slowly climbing.

In 1996, outdoor outfitter Patagonia switched to $100 \%$ organic fiber for all its sportswear and technical outdoor clothing; the Ventura-based company is also purchasing transitional cotton to encourage farmers to make the switch.
Likewise, Nike is now blending 3\% organic fiber into millions of T-shirts manufactured in the United States, with a goal of using $3 \%$ organic fiber in all its cotton clothing by 2003.

In general, U.S. consumers are showing increasing interest in organic products, primarily due to concerns about health and the environment. Estimated retail sales of organic foods and products were $\$ 4.2$ billion in 1997 ; the market has been growing about $20 \%$ annually throughout the 1990s, according to the Organic Trade Association.

"There is no reason for manufacturers not to use organic cotton," says Sandra Marquardt of OFC. "Although the price per pound is higher, when you look at the overall cost of the finished product the fiber costs are minuscule." Nike estimates its current cost to use organic fiber at 2 cents per T-shirt.

\section{Research needs}

In general, very little research has been conducted directly on organic cotton in California or anywhere else. But the IPM methods being utilized by all California cotton growers - including organic - have been developed over five decades by UC and other scientists.

Cotton insect pest management has come a long way, Goodell says. Today's pest management methods include plant mapping, insect monitoring, economic thresholds, nutrient and water management, intercropping, and using uncut alfalfa strips and beans to create habitat for beneficial insects and to mitigate pest movement with crops.

"Knowledge developed for conventional farmers is useful for organic farmers," Goodell says. "We are working with alternative technologies to keep the insects out of the field in the first place."

California's organic cotton growers can provide a "living laboratory" for studying reducedinput methods applicable to cotton growing statewide, Goodell says.

Cotton growing requires intensive management and high levels of skill and knowledge, Swezey says, but there is little research specifically geared to organic cotton farming.

"We would like to continue our organic cotton research," Swezey says. "Our partnership with growers has shown us the potential for organic production systems. An increased commitment to research is very important if this industry is going to move forward."

$$
-J \cdot B
$$

